\title{
Symbiosis of Monetary and Fiscal Policies in a Monetary Union*
}

\author{
by \\ Avinash Dixit, Princeton University \\ and \\ Luisa Lambertini, UCLA \\ First draft - August 13, 1999 \\ This draft — February 20, 2002
}

\begin{abstract}
We consider the interaction between the monetary policy in a monetary union, and separate fiscal policies of the member countries. We use a Barro-Gordon type model extended to many countries and fiscal policies. Each country's fiscal policies inflict externalities on other countries, and the common monetary policy has its timeconsistency problem. But if the two types of policymakers agree about the ideal levels of output and inflation, then this ideal is attained despite disagreements about the weights of the objectives, despite ex post monetary accommodation to fiscal profligacy, without fiscal coordination, without monetary commitment, and for any order of moves.

JEL Classification: F33, F42

Keywords: monetary union, monetary policy, fiscal policy.

Addresses of authors:

Avinash Dixit, Department of Economics, Princeton University, Princeton, NJ 08544-1021, USA. E-mail: dixitak@princeton.edu

Luisa Lambertini, Department of Economics, University of California, Los Angeles, CA 90095-1477, USA. E-mail: luisa@econ.ucla.edu
\end{abstract}

\footnotetext{
${ }^{*}$ We thank Michael Woodford, Roel Beetsma the editors and two anonymous referees for useful suggestions. Dixit thanks the National Science Foundation and Lambertini thanks the UCLA Senate for financial support.
} 


\section{Introduction}

The Economic and Monetary Union (EMU) of Europe has a common central bank (ECB) that conducts a common monetary policy, but each country's fiscal policy is determined by its own government. It is generally believed that the arrangement will lead to excessive deficits, as each government engages in fiscal expansion to increase its own GDP, and expects to pass on some of the cost of its fiscal profligacy to other countries in the form of higher common inflation and interest rates. The Maastricht Treaty and subsequent agreements have tried to guard against this by stipulating that each country's fiscal deficit in each year should not exceed 3 percent of its GDP, and forbidding the ECB from financing any member country's deficits or bailing out a country even in a fiscal crisis. Of course the EMU is ultimately a political organization, and the credibility of these provisions is always open to doubt. The constraint on fiscal policies has been criticized in the economics literature for being too strict and too inflexible; see Buiter, Corsetti and Roubini (1993) and the discussion that follows. Therefore politicians who wish to create and exploit escape clauses around the constraints have respectable arguments on their side. Some flexibility is already beginning to appear in the practical application of the constraints, as countries like France and Italy facing high unemployment are being given room to have temporarily higher deficits.

The ability of each country to choose its own fiscal policy leads to an equilibrium that is suboptimal for them all because of interactions or externalities. Fiscal policy has many aspects, and each can create positive or negative externalities. For example, public goods in one country can have positive or negative spillovers for its neighbors; one country's fiscal expansion can benefit employment in the others through demand spillovers or hurt them through higher interest rates or higher inflation. Noncooperative fiscal choices of the countries will lead to a Nash equilibrium with more spending and deficits than in a cooperative optimum if the externalities are negative, and too much restriction if they are positive.

For monetary policy, even with one country, we have the well-known time-consistency problem. With several countries facing asymmetric shocks, this problem can be aggravated as at any time, one country or another may suffer a bad supply shock and therefore have 
a strong reason to want the common central bank to expand employment using surprise inflation. Dixit (2000) analyzes such a game among the member countries.

Monetary and fiscal policies in a union thus have their own problems, but the new feature of the EMU is the interaction between a centralized monetary policy and a decentralized fiscal policy.

When the monetary and fiscal authorities in a monetary union agree on the ideal output and inflation levels, we show that the ideal outcomes emerge as the equilibrium without the need for monetary commitment, irrespective of which authority moves first and despite any disagreement on the relative weights of the two objectives.

When the authorities concur on the bliss point, fiscal instruments can be a better way of achieving the countries' desired output levels than attempts to create surprise inflation; thus fiscal policies can help avoid the time-consistency problem of monetary policy, despite the failure of the countries to coordinate their fiscal policies directly. Even if a fiscal expansion has inflationary consequences or is met by an ex post monetary accommodation contrary to the strict stipulation of the Maastricht treaty, an offsetting advance adjustment of monetary policy handles this problem.

In other words, our model demonstrates a possible symbiosis between the uncoordinated fiscal policies of the member countries and the monetary policy of the common central bank of the union. Each type of policy helps mitigate the problem created by the other, and together they can achieve the ideal outcomes.

We mention two policy discussions in this context before giving a more detailed review of the literature. Buiter, Corsetti and Roubini (1993, pp. 78-9) claim that negative fiscal externalities are not of much quantitative significance in the EMU. However, that remains debatable, and the discussion of the paper offers just such a debate. Good quantitative evidence is lacking. Our findings may make the issue moot. Dornbusch (1997) argues that fiscal constraints are justified on theoretical grounds but in practice the central bank's commitment may make them unnecessary. (His theoretical model has only one country, however.) We offer a theoretical argument why fiscal restraints may be redundant, even when the central bank is not as committed or conservative in practice as the EMU's constitution 
requires it to be in principle. But our assumption of identical ideal points is important here; we relax it in $(2000,2001)$ and elucidate the role of fiscal constraints.

\section{Literature Review}

There have been several studies of monetary-fiscal interaction in a monetary union. Most of them consider the purpose of fiscal policy to be the provision of public goods; for example Sibert (1992), Levine and Brociner (1994), Beetsma and Bovenberg (1998). However, much of the debate about the fear of excessive fiscal expansion has been about the countercyclical role of fiscal policy; that is of special interest in the EMU since unemployment has been the most pressing problem in many of its member countries for the last few years and is likely to remain so for the next few. Therefore in this paper we focus on this aspect.

Other works have studied the desirability of fiscal constraints within a monetary union. The Pact for Stability and Growth sets limits on the debt and on general government deficit ratios for the EMU members and it provides for penalties for the countries that exceed such limits. On one hand, Chari and Kehoe (1998) and Dornbusch (1997) argue that fiscal constraints are not necessary, and possibly harmful, when the monetary authority can commit its policies; on the other hand, Beetsma and Bovenberg (1999) and Beetsma and Uhlig (1999) argue that fiscal constraints improve welfare because they correct the debt bias stemming from government myopia. We offer a theoretical argument why fiscal constraints may be redundant independently of whether the monetary authority is ultraconservative or can commit its policies ex ante.

The existing studies on the welfare effects of fiscal coordination within a monetary union generate conflicting results. Fiscal coordination is beneficial when there is a free-rider problem that results in too much debt being issued, as in Chari and Kehoe (1998) and Huber (1998). In the model of Beetsma and Bovenberg (1998), however, fiscal cooperation harms welfare when it is set before monetary policy because it enhances the strategic position of fiscal authorities vis-a-vis the monetary authority. With monetary commitment, debt is too high from a social welfare perspective but not the government's perspective, given its myopia. Our paper contributes to this policy debate on the need to coordinate fiscal policies 
in the EMU by showing that non-cooperative fiscal stabilization policy is not an obstacle to the achievement of the desired policy goals.

Canzoneri (1985) presents a Barro-Gordon stochastic setting (without fiscal policy) where the central bank has private information in the sense that private agents cannot observe, or cannot reconstruct, the actual stochastic shocks; Cukierman and Meltzer (1986) have a model where the central bank's preferences on inflation and output shift stochastically through time and are not known to private agents. With asymmetric information, the central bank has an incentive to misrepresent its information in an effort to expand output, thereby generating inflation. Our model is one of symmetric information: the realization of the stochastic shocks is not observed by private agents before inflationary expectations are set, but it is perfectly observed afterward. Full transparency of the central bank's intentions delivers the ideal outcome in our model and is therefore beneficial.

Banerjee (1997) uses a model similar to ours in many respects. But first he considers only the pure time-consistency problem in a non-stochastic environment, and when later he introduces two additive stochastic shocks, allows only policy commitments to fixed numbers rather than any state-contingent rules, linear or otherwise.

The literature on discretion and commitment since the works of Kydland and Prescott (1977) and Barro and Gordon (1983) assumes that policymakers have preferences over inflation and employment that correspond to a quadratic loss function. We follow the literature on this assumption. Rotemberg and Woodford (1997) derive a quadratic loss function that is an approximation to the level of expected utility of the representative agent in the rational expectations equilibrium associated with a given policy.

\section{The Model}

Our working model is a reduced form of the Barro-Gordon (1983) type, extended to the case

of many countries, and to include fiscal as well as monetary policy. Appendix $\mathrm{A}^{1}$ presents a micro-founded model whose log-linearization around the steady state delivers equations (1) and (3) below; thus our analysis and its results can be justified as long as the economy is not far from the steady state. 
The monetary union consists of member countries $i=1,2, \ldots n$. Thus the membership is fixed; entry and exit are not considered in this paper. The union has a common central bank, which chooses a policy variable $\pi_{0}$. Each country has a fiscal authority, and the fiscal policy variables are denoted by $x_{i}$. A larger $x_{i}$ means a more expansionary fiscal policy. These policies result in GDP levels $y_{i}$ in the separate countries, and a common inflation level $\pi$. Let $\pi^{e}$ denote the private sector's rational expectation of $\pi$.

The GDP levels of the countries are given by

$$
y_{i}=\bar{y}_{i}+\sum_{j} a_{i j} x_{j}+b_{i}\left(\pi-\pi^{e}\right)
$$

The parameter $\bar{y}_{i}$ can be interpreted as a measure of the natural private output in country $i$. Each $a_{i i}$ shows the effect on GPD of that country's own fiscal policy, and the $a_{i j}$ for $j \neq i$ are the spillovers of one country's fiscal policy on others. In the model of appendix A, lower distortionary taxation or a production subsidy have an expansionary effect on own and foreign $\operatorname{GDP}\left(a_{i i}>a_{i j}>0\right)$ while an increase in government spending financed by distortionary taxes has a contractionary effect on own and foreign GDP $\left(a_{i i}<a_{i j}<0\right)^{2}$. The algebra of the model works perfectly well no matter the sign of all these coefficients, thus permitting negative or positive fiscal externalities. All we require is that the matrix $A=\left(a_{i j}\right)$ is nonsingular. The last term of the right-hand side of (1) is the usual supply effect of surprise inflation; as shown in appendix $\mathrm{A}, b_{i}>0$ and its magnitude can differ across countries.

The equations (1) for all countries can be collected into one, using the obvious vector and matrix notation, as

$$
y=\bar{y}+A x+\left(\pi-\pi^{e}\right) b
$$

The common inflation level is given by

$$
\pi=\pi_{0}+c \sum_{i} x_{i}=\pi_{0}+c e^{\prime} x
$$

where $e$ is the $n$-dimensional unit vector and prime denotes transposes. Inflation is a sum of the component $\pi_{0}$, which represents its initial stance or the controlled part of monetary policy, and a further contribution arising from fiscal policies $c$. A fiscal expansion of demand, 
especially if financed by distortionary taxation which reduces supply, puts an upward pressure on prices; or the central bank may decide to make some ex-post accommodation of fiscal expansion. In the EMU, such accommodation is not supposed to be made, but in practice some is likely to occur; see the discussion following Buiter, Corsetti and Roubini (1993). In both cases, $c>0$. However, a supply-side fiscal policy, such as a tax cut or a production subsidy or public investment that raises private productivity, can increase the supply of goods and services and may also lower private demand when financed by taxation of incomes. Then $c<0$ may occur. The algebra of the model works perfectly well in either case and even if $c=0$. But more importantly, our results are valid even with $c>0$, that is, even a monetary accommodation of fiscal expansion, despite the stipulations of Maastricht, or direct inflationary consequences of fiscal policies do not interfere with the attainment of the ideal output and inflation levels.

The vector $\bar{y}$ of natural output levels, the matrix $A$ of fiscal policy own and cross effects, the vector $b$ of the supply effects of surprise inflation, and the scalar parameter $c$ are all stochastic shocks. We denote the whole vector of these shocks by $z=(\bar{y}, A, b, c)$. The policy variables $\pi_{0}$ and $x$ are implemented after the shocks are observed, and should be written as $\pi_{0}(z)$ and $x(z)$; to keep the notation simple, however, we drop the dependence on $z$ whenever it does not create confusion. The private sector's expectations are formed before any of these shocks are realized, and are rational, that is, $\pi^{e}=\mathrm{E}[\pi]$.

The countries want to minimize their respective loss functions defined by

$$
L_{i}=\frac{1}{2} \theta_{i}\left(y_{i}^{*}-y_{i}\right)^{2}+\frac{1}{2} \pi^{2} .
$$

The parameter $y_{i}^{*}$ represents the output goal for the fiscal authority in country $i$. For example, in the model of appendix A, natural output $\bar{y}_{i}$ is inefficiently low because of the monopoly power over produced goods and $y_{i}^{*}$ could be the optimal level of output for the representative agent in the absence of distortions from monopolistic competition and pre-set prices. Achieving $y_{i}^{*}$ by eliminating the distortions (monopolistic competition and pre-set prices) delivers the first best; but achieving $y_{i}^{*}$ by using distortionary fiscal policy may not deliver the first best. Hence, in the presence of distortionary taxation, $y_{i}^{*}$ may represent an 
appropriate second best. In general, we have in mind a situation where $\bar{y}_{i}<y_{i}^{*}$, so extra output is desirable.

$\theta_{i}$ parameterizes the country's preference for higher output relative to its dislike of inflation. We take $\theta_{i}>0$ and finite; the case where the fiscal authority does not care about inflation at all corresponds to the limit where $\theta_{i} \rightarrow \infty$. The inflation goal for the fiscal authority is zero. In the model of appendix A, the loss function that approximates the level of expected utility of the representative agent is quadratic in the output gap $\left(y_{i}-y_{i}^{*}\right)$ and in the deviation from expected inflation $\left(\pi-\pi^{e}\right)$. But in a more general setting, inflation may be costly for any underlying structural reason, including higher nominal interest rates. Our result remains unchanged for an ideal inflation $\pi^{*} \neq 0$, so long as both the fiscal and monetary authorities agree on it.

When fiscal policies are coordinated, we suppose that the union-wide objective of the joint fiscal decision-maker is to minimize a weighted average of the member countries' loss functions:

$$
L^{F}=\sum_{i} \omega_{i} L_{i}
$$

where the weights $\omega_{i}$ are positive and sum to 1 . Using vector notation, this can be written as

$$
L^{F}=\frac{1}{2}\left[\left(y^{*}-y\right)^{\prime} \Theta \Omega\left(y^{*}-y\right)+\pi^{2}\right]
$$

where $\Omega$ and $\Theta$ are diagonal matrices with entries $\omega_{i}$ and $\theta_{i}$ respectively. ${ }^{3}$

The common central bank minimizes its loss function, which is given by

$$
L^{M}=\frac{1}{2}\left[\delta\left(y^{*}-y\right)^{\prime} \Theta \Omega\left(y^{*}-y\right)+\pi^{2}\right]
$$

where $\delta \geq 0$. The central bank is more conservative, as in Rogoff (1985), than the fiscal authorities if $\delta<1$. The Maastricht treaty, by making inflation the European Central Bank's primary objective, makes it ultraconservative with $\delta=0$. This may or may not be how the bank functions in practice, but our results are valid for arbitrary $\delta \geq 0$, indeed even for $\delta>1$ where the bank is less conservative than the fiscal authorities.

There is one common aspect to the loss functions of the two authorities: the fiscal objectives and the central bank's objective have the same ideal outcomes, namely $y_{i}=y_{i}^{*}, \forall i$ 
and $\pi=0$, and this is true for any $\delta .^{4}$ This is the key assumption to our result that the ideal outcomes emerge as the equilibrium under all the alternative rules of the game we consider below. The result that, if there is agreement as to what is ideal then that outcome results irrespective of the rules of the game, depends crucially on two features: [1] The equilibrium of the game is unique. [2] The equilibrium has a unique strategy set that implements it. We pay attention to both these matters.

The sequence of actions is as follows:

1. If the monetary policy regime is one of commitment, the central bank chooses its policy rule $\pi_{0}=\pi_{0}(z)$ where $z=(\bar{y}, a, b, c)$; this specifies how it will respond to the stochastic shocks. If the monetary regime is one of discretion, nothing happens at this step.

2. The private sector forms expectations $\pi^{e}$.

3. The stochastic shocks $\bar{y}, a, b, c$ are realized.

4. (a) If the monetary policy regime is one of discretion, the central bank chooses $\pi_{0}$. If the monetary regime is one of commitment, the central bank simply implements the monetary rule $\pi_{0}$ that was chosen at step 1 .

(b) The country governments choose fiscal policies $x_{i}$. There are two cases, one where the countries cooperate in this choice, and the other where they act independently resulting in a Nash equilibrium.

When monetary policy is discretionary, the relative timing of step 4 (a) and 4 (b) raises some questions. In fact, monetary and fiscal policies can be chosen simultaneously or the order of 4 (a) and 4 (b) can be reversed. Monetary policy can be committed or discretionary, and fiscal policy can be cooperative or noncooperative. Thus there can be four different regimes; we prove that the ideal outcome emerges as the equilibrium in all regimes and irrespective of the order of moves. 


\section{Best response functions}

We begin by considering each policymaker's ex post best response to given strategies of the others. This lays the foundation for the characterization of all types of equilibria. The central bank chooses its action $\pi_{0}$ at step 4 (a), taking $x$ as given, so as to minimize $L^{M}$. The fiscal choice of government $i, x_{i}$, is made at step 4 (b), taking $\pi_{0}$ and all other fiscal choices $x_{j}$ with $j \neq i$ as given, so as to minimize $L_{i}$. The $n$ fiscal authorities and the common central bank act simultaneously; we consider both the cases where they act cooperatively and non-cooperatively.

\subsection{Fiscal non-cooperative best response functions}

The first-order condition for the fiscal policy of country $i$ is obtained by differentiating $L_{i}$ in (4) with respect to $x_{i}$, taking monetary policy $\pi_{0}$ as given but recognizing the dependence of $\pi$ on $x_{i}$. When $x_{i}$ is chosen, the private sector's expectations $\pi^{e}$ are fixed. We obtain

$$
0=\frac{\partial L_{i}}{\partial x_{i}}=-\theta_{i}\left(y_{i}^{*}-y_{i}\right)\left(a_{i i}+c b_{i}\right)+c \pi .
$$

Since the fiscal authorities act noncooperatively, each one of them fails to internalize the effect of its own fiscal policy on the GDPs of the others; in fact, the first-order condition (8) depends only on $a_{i i}$. However, the government of country $i$ takes into account the inflationary consequences of its fiscal policy and their direct and indirect effects on $L_{i}$. (8) defines the reaction function of the fiscal authority $i$. Let

$$
h_{i} \equiv \frac{c}{\theta_{i}\left(a_{i i}+c b_{i}\right)}
$$

and $h$ the vector with components $h_{i}$. Then the conditions in vector form are

$$
y^{*}-y=h \pi
$$

This defines the reaction functions of all fiscal authorities in the monetary union in the $(y, \pi)$ space. Substituting $y$ and $\pi$ into (9) using (2) and (3), we can obtain the fiscal reaction functions in terms of the policy variables $x, \pi_{0}$. 


\subsection{Fiscal cooperative best response function}

The fiscal choices $x$ are made to minimize the union-wide loss $L^{F}$. The monetary policy is discretionary, so $\pi_{0}$ is a free choice variable at this point, and the objective is to minimize $L^{M}$. But the private sector's expectations $\pi^{e}$ are fixed when the monetary and fiscal policies are chosen.

Differentiating (5) gives us the following first-order conditions for fiscal policy $x_{j}$ in country $j$ :

$$
\begin{aligned}
0 & =\sum_{i} \omega_{i} \frac{\partial L_{i}}{\partial x_{j}} \\
& =-\sum_{i} \omega_{i} \theta_{i}\left(y_{i}^{*}-y_{i}\right)\left(a_{i j}+c b_{i}\right)+c \pi,
\end{aligned}
$$

or in vector notation

$$
c \pi e^{\prime}=\left(y^{*}-y\right)^{\prime} \Theta \Omega\left(A+c b e^{\prime}\right)
$$

where $e$ denotes the $n$-by-1 unit matrix.

\subsection{Monetary best response function}

The first-order condition for monetary policy is obtained by differentiating $L^{M}$ in (7) with respect to $\pi_{0}$, taking the vector of fiscal policy $x$ as given. Once again, the private sector's expectations are already fixed at this point. This gives

$$
0=\frac{\partial L^{M}}{\partial \pi_{0}}=-\delta \sum_{i} \omega_{i} \theta_{i}\left(y_{i}^{*}-y_{i}\right) b_{i}+\pi,
$$

or, in vector notation,

$$
\pi=\delta\left(y^{*}-y\right)^{\prime} \Theta \Omega b
$$

This defines the reaction function for the monetary authority in the $(y, \pi)$ space. Again, if we substitute $y$ and $\pi$ into (11) using (2) and (3), the first-order condition for the monetary authority can be written in terms of the policy variables $\pi_{0}$ and $x$. 


\section{Equilibria}

Now we can use the best response functions to construct complete equilibria. The general idea is that the outcome $y=y^{*}, \pi=0$ is ideal for all players and for all realizations of the shocks, and therefore it is desirable for all; it only remains to check that it can be attained using the available strategies $x$ and $\pi_{0}$, and that the rationality of expectations can be sustained. The intuition for our result that the ideal output and inflation levels are attained for any structure of the game is simple. There are $(n+1)$ objectives and $(n+1)$ policy

instruments; hence, the objectives can be achieved. Disagreement about the weights of the objectives among the policymakers gives different slope to their best response functions; but they all intersect at the ideal levels of output and inflation.

\subsection{Discretionary Nash Equilibrium}

Consider the case where the fiscal authorities of different countries act non-cooperatively; the case where they act cooperatively follows the same lines.

The best response functions, (9) for fiscal policies and (11) for monetary policy, have an obvious solution, namely $y=y^{*}$ and $\pi=0$. These are $(n+1)$ linear equations in $(n+1)$ unknowns; therefore the solution is generically unique, that is, unique except for a subset of coefficients, and therefore except for a subset of shocks $z$ that is of measure zero in the relevant space.

The strategy choices $x$ and $\pi_{0}$ that correspond to this solution can be found from (2) and (3). Since $\pi=0$ for almost all $z$, the rational expectation is $\pi^{e}=0$. Then the solution is

$$
x=A^{-1}\left(y^{*}-\bar{y}\right)
$$

and

$$
\pi_{0}=-c e^{\prime} A^{-1}\left(y^{*}-\bar{y}\right)
$$

which is again generically unique due to the linearity of the output and inflation equations (2) and (3). 


\subsection{Discretionary Monetary Leadership}

Here the monetary authority commits itself to a policy rule or function $\pi_{0}(\cdot)$. Then expectations are formed, and the shocks are realized. Finally, fiscal policies are chosen. Again focus on the case where the fiscal authorites act non-cooperatively. At this point they already know what the monetary policy is going to be, namely $\pi_{0}(z)$. We show that the monetary authority can achieve the ideal point in this situation.

Suppose the monetary authority chooses its rule $\pi_{0}(\cdot)$ according to (13) above, and the fiscal authorities respond by choosing $x$ according to (12) above. This yields $\pi=0$ for all $z$. Then $\pi^{e}=0$, and

$$
y=\bar{y}+A A^{-1}\left(y^{*}-\bar{y}\right)+b(0-0)=y^{*} .
$$

Then the fiscal best response equations (12) are satisfied, so this is indeed the fiscal authorities' best response. And since the outcome is the monetary authority's ideal, the policy we stipulated is indeed its best leadership strategy. We can also work back from the ideal outcome and see that these strategies are the generically unique way of attaining that outcome.

\subsection{Other Possibilities}

The analysis of all other equilibria follows the same lines, and all yield the common ideal outcome.

We summarize our results in the following proposition.

Proposition 1 If the monetary and fiscal authorities have identical output $\left(y_{i}^{*}, \forall i\right)$ and inflation $\left(\pi^{*}\right)$ goals, those goals can be achieved without the need for fiscal coordination, without the need for monetary commitment, irrespective of which authority moves first and despite any disagreement about the relative weights of the two set of objectives.

\section{Limitations and Extensions}

Our simple model led to some clear results, and quite optimistic ones for the enterprise of the EMU. Despite the presence of fiscal externalities and the time consistency problem of monetary policy, the ideal output and inflation levels are achievable. This occurs even without 
monetary policy commitment, and without the need to have a conservative common central bank. The European Central Bank is supposed to be committed to an ultraconservative objective; our model says that these requirements are unnecessary. The Maastricht Treaty and the Pact for Stability and Growth place additional restraints on the member countries' fiscal policies to achieve some coordination and cope with externalities; in our model these too are unnecessary. If the additional constraints alter the reaction functions of the game of fiscal interaction and thereby change its Nash equilibrium, such constraints may even prove counterproductive.

The essential feature that generates these results is the agreement between the central bank and the fiscal authorities on the most desirable level of output in each country and the most desirable level of inflation. With such agreement, there is a mutually beneficial interaction, one might say a symbiosis, between monetary and fiscal policies. The fiscal policy variables are better instruments than inflation for achieving the countries' ideal output levels; when they are present the monetary policy can avoid the time-consistency problem. And monetary restraint can be deployed in anticipation of, or in response to, the countries' fiscal expansion attempts, in such a way as to neutralize their inflationary consequences.

If there is a conflict of objectives between the central bank and the fiscal authorities, Dixit and Lambertini (2000, 2001) show that the equilibrium outcomes do not coincide with the bliss point and that they depend on the details of the institution, such as commitment and order of moves.

We interpret our result - the desired output and inflation levels can be achieved without the need for fiscal coordination, without the need for monetary commitment, irrespective of which authority moves first and despite any disagreement about the relative weights of the two objectives - in a normative manner. If the authorities' preferences can be chosen in advance and can be made to coincide, the ideal inflation and output levels can be attained independently of the details of the institutions. There is a case for bringing the monetary and fiscal policy goals together rather than setting up fiscal limits and a mechanism of monetary commitment.

Of course our model made several special assumptions, and altering or relaxing them may change some of the results. First and most important, the result depends on the agreement 
about the ideal output and inflation levels. One might hope that European integration itself will lead to such convergence of preferences, but that is not guaranteed. The result may also depend on some substantive economic assumptions we made. Many features of our model of fiscal policies are specific to the countercyclical or stabilization function; similar results may not be valid for other functions like redistribution or public good provision. Next, the ideal output and inflation levels do not coincide with the true first best when fiscal instruments are distortionary and create dead-weight losses. Our analysis did not consider the welfare implications of such distortions. In principle, the output and inflation ideal levels may be the appropriate second best in a welfare maximizing setting; but this seems to be an interest topic for future research.

More subtly, in an infinite-horizon intertemporal model with present value budget constraints, monetary policy may not be able to maintain price stability for arbitrary fiscal policies; see Woodford (1998). Of course, in an infinite-horizon context the game among countries over fiscal policies and the further game with the common central bank over monetary policy are both repeated games, and may produce better equilibria using suitably designed punishments; see Dixit (1998) for such a model of monetary policy alone. 


\section{Notes}

${ }^{1}$ Available at the following web sites:

http://www.econ.ucla.edu/lambertini/

http://www.princeton.edu/ dixitak/home/

${ }^{2}$ The expansionary impact of an increase in government spending is more than offset by the contractionary impact of lower labor supply and lower private demand due to higher distortionary taxes. Since total demands for foreign goods falls, foreign output also falls.

${ }^{3}$ Since inflation is common in the monetary union and the $\omega_{i}$ s sum up to 1 , the squared inflation term in (6) is multiplied by $1 / 2$.

${ }^{4}$ We could have allowed a non-zero common ideal inflation rate $\pi^{*}$ at the cost of notational complexity. 


\section{References}

Banerjee, Gaurango. 1997. Rules and Discretion with Separate Fiscal Authorities and a Common Monetary Authority. Doctoral dissertation. Tuscaloosa, AL: University of Alabama.

Barro, Robert J. and David B. Gordon. 1983. "A Positive Theory of Monetary Policy in a Natural-rate Model." Journal of Political Economy, 91(3), June, 589-610.

Beetsma, Roel M. W. J. and A. Lans Bovenberg. 1998. "Monetary Union without Fiscal Coordination May Discipline Policymakers." Journal of International Economics, 45, $239-258$.

Beetsma, Roel M. W. J. and A. Lans Bovenberg. 1995. "Does Monetary Unification Lead to Excessive Debt Accumulation?" Journal of Public Economics, 74, December, 299-325.

Beetsma, Roel and Harald Uhlig. 1999. "An Analysis of the Stability and Growth Pact," Economic Journal, 109(458), October, 546-571.

Buiter, Willem, Giancarlo Corsetti and Nouriel Roubini. 1993. "Excessive deficits: Sense and nonsense in the Treaty of Maastricht." Economic Policy, 16, April, 58-100.

Canzoneri, Matthew. 1985. "Monetary Policy Games and the Role of Private Information," American Economic Review, 75(5), December, 1056-1070.

Chari, V. V. and Patrick Kehoe. 1998. "On the Need for Fiscal Constraints in a Monetary Union," Federal Reserve Bank of Minneapolis, Working paper 589, August.

Cukierman, Alex and Allan Meltzer. 1986. "A Theory of Ambiguity, Credibility, and Inflation Under Discretion and Asymmetric Information," Econometrica, 54(5), September, 1099-1128.

Dixit, Avinash. 2000. "A Repeated Game Model of Monetary Union." Economic Journal, 110, October, forthcoming.

Dixit, Avinash and Luisa Lambertini. 2000. "Fiscal Discretion Destroys Monetary Commitment." Princeton University and UCLA, Working paper. 
Dixit, Avinash and Luisa Lambertini. 2001. "Monetary-Fiscal Policy Interactions and Commitment Versus Discretion in a Monetary Union," European Economic Review, (45)4-6, pp. $977-987$.

Dornbusch, Rudiger. 1997. "Fiscal Aspects of Monetary Integration." American Economic Review, 87(2), Papers and Proceedings, May, 221-223.

Huber, Bernd. 1998. "Credibility, Seignorage and Government Debt" in The Debt Burden and its Consequences for Monetary Policy, eds. Guillermo Calvo and Mervyn King, New York: St. Martin's Press.

Kydland, Finn and Edward Prescott. 1977. "Rules Rather Than Discretion: The Inconsistency of Optimal Plans." Journal of Political Economy, 85, 473-490.

Levine, Paul and Andrew Brociner. 1994. "Fiscal Policy Coordination and EMU: A Dynamic Game Approach." Journal of Economic Dynamics and Control, 18(3/4), May/July, 699729.

Rogoff, Kenneth. 1985. "The Optimal Degree of Commitment to an Intermediate Monetary Target," Quarterly Journal of Economics, 100(4), November, 1169-1189.

Rotemberg, Julio and Michael Woodford. 1997. "An Optimization-Based Econometric Framework for the Evaluation of Monetary Policy." NBER Macroeconomic Annual, $12,297-346$.

Sibert, Anne. 1992. "Government Finance in a Common Currency area." Journal of International Money and Finance, 11, 567-578.

Woodford, Michael. 1998. "Control of the Public Debt: A Requirement for Price Stability?" In The Debt Burden and Its Consequences for Monetary Policy, eds. Guillermo Calvo and Mervyn King, New York: St. Martin's Press, 117-154. 